\title{
Proposta de avaliação do comportamento tático de jogadores de Futebol baseada em princípios fundamentais do jogo
}

\author{
Israel Teoldo da Costa ${ }^{1}$ \\ Júlio Garganta ${ }^{3,4}$ \\ Pablo Juan Greco 2 \\ Isabel Mesquita ${ }^{3,4}$ \\ ${ }^{1}$ Núcleo de Pesquisa e Estudos em Futebol, Universidade Federal de Viçosa, Viçosa, \\ MG, Brasil \\ ${ }^{2}$ Universidade Federal de Minas Gerais, UFMG, Belo Horizonte, MG, Brasil. \\ ${ }^{3}$ Faculdade de Desporto da Universidade do Porto, FADEUP, Porto, Portugal. \\ ${ }^{4}$ Centro de Investigação, Formação, Inovação e Intervenção em Desporto, Portugal.
}

\begin{abstract}
Resumo: Os instrumentos disponíveis para a avaliação do conhecimento tático processual em Futebol têm resultado de uma abordagem vaga, no que respeita à especificidade do jogo. O presente artigo tem por objetivo fundamentar conceitualmente a construção de um modelo de avaliação dos comportamentos táticos de jogadores, com base em princípios táticos fundamentais do jogo. A proposta aqui detalhada busca evidenciar a essencialidade tática do jogo e estabelecer um vínculo entre a informação proveniente da avaliação do jogador e suas implicações na transformação positiva do processo de ensino e treino.
\end{abstract}

Palavras-chave: Futebol. Princípios táticos. Avaliação. Tática. Conhecimento tático processual.

\section{Proposal for tactical assessment of Soccer player's behaviour, regarding core principles of the game}

\begin{abstract}
The tactical procedural knowledge assessment has displayed scarce approach concerning characteristics of Soccer game, specially, in the teaching context. This paper aims to show a proposal of tactical behavior evaluation of soccer player which takes account fundamentals tactical principles of Soccer game. This proposal tries to reflect specificity of the Soccer context and to establish a connection between the contents of training sections and assessment of the tactical development of players in all formations stages.
\end{abstract}

Key Words: Soccer. Tactical Principles. Evaluation. Tactics. Tactical procedural knowledge.

\section{Introdução}

A avaliação tática no âmbito do Futebol tem sido objeto de estudo de muitos pesquisadores que objetivam construir instrumentos capazes de avaliar adequadamente os constrangimentos relacionados com o desempenho dos jogadores durante o jogo (TENGA et al., 2009). Os instrumentos para a avaliação do comportamento tático, descritos na literatura, se distinguem com base em dois tipos de conhecimento avaliados: 0 conhecimento declarativo e o conhecimento processual. O conhecimento declarativo refere-se à capacidade do praticante em declarar de forma verbal e/ou escrita qual a melhor decisão a ser tomada em uma determinada situação de treino ou de jogo e o porquê desta decisão (TENENBAUM; LIDOR, 2005). Já o conhecimento processual está relacionado à capacidade do jogador em operacionalizar respostas apropriadas aos problemas advindos das situações de treino e jogo, estando intimamente ligado a ação motora (WILLIAMS; DAVIDS, 1995; KIRKHART, 2001).

Os estudos realizados para avaliar 0 conhecimento tático declarativo do praticante se consubstanciam, principalmente, na apresentação de diapositivos com situações pré-definidas de jogo e na utilização de questionários e entrevistas (FRENCH; THOMAS, 1987; MANGAS; GARGANTA; FONSECA, 2002). A realização de estudos com este cariz tem contribuído para a avaliação do conhecimento que suporta a realização da ação em situações de jogo (BARD; FLEURY, 1976). Todavia, as limitações desses instrumentos decorrem da dificuldade de simular com fidedignidade o comportamento do jogador em cenários reais de jogo ou de treino, nos quais os aspectos ambientais influenciariam as suas decisões. Por esse motivo, alguns autores têm considerado que os testes de conhecimento declarativo, recorrentemente utilizados, não permitem obter informação representativa acerca 
da capacidade de pensamento e de tomada de decisão do praticante em função de uma situação real de jogo (BLOMQVIST; VÄNTTINEN; LUHTANEN, 2005).

No que reporta a avaliação do conhecimento tático processual destacam-se três instrumentos que estão diretamente relacionados com 0 processo de ensino e treino: o Game Performance Assessment Instrument - GPAl (OSLIN; MITCHELL; GRIFFIN, 1998), o Team Sports Performance Assessment Procedure - TSAP (GRÉHAIGNE; GODBOUT; BOUTHIER, 1997) e a bateria de testes KORA (MEMMERT, 2002). O GPAl, apropriado especificamente para ser utilizado em níveis mais elementares de prática, permite identificar os comportamentos dos jogadores no jogo, incluindo não só os indicadores de natureza técnica, mas prioritariamente os de natureza tática. O TSAP foi desenvolvido para providenciar informações sobre o desempenho dos jogadores no que refere aos comportamentos realizados durante a fase ofensiva do jogo. Já o KORA centra as suas análises em dois parâmetros táticos comuns as modalidades esportivas nas quais as estruturas do jogo se caracterizam pela invasão do campo adversário (oferecer-se e orientar-se, reconhecer espaços de jogo); sendo a avaliação realizada sob as perspectivas convergente e divergente, que se relacionam com a inteligência e a criatividade de jogo. Os dois primeiros instrumentos (GPAl e TSAP), no sentido de obter um índice de desempenho, têm recorrido a variáveis compostas na tentativa de ponderar as ações realizadas em função do contexto e das especificidades do jogo.

A utilização desses instrumentos para a avaliação do comportamento tático do praticante tem contribuído para a aproximação dos resultados obtidos no teste com o desempenho apresentado no jogo (LEE; WARD, 2009). Além disso, dois dos instrumentos apresentados (KORA e GPAI) representam avanços ao nível da avaliação do comportamento tático do jogador no jogo, no que diz respeito às interações de jogo e a consideração das movimentações de todos os jogadores envolvidos, com e sem posse de bola. Não obstante a essas contribuições, estes dois instrumentos não são sensíveis à identificação de variáveis nucleares que representam a especificidade do jogo de Futebol. Já o TSAP apresenta uma avaliação mais próxima aos comportamentos desempenhados pelos jogadores de Futebol, devido considerar os próprios ambiente e espaço de jogo e o estatuto posicional dos jogadores. Entretanto a sua debilidade recai sobre a ausência de consideração das interações de jogo e de avaliação dos comportamentos relacionados a fase defensiva.

Em face destas limitações, torna-se evidente a necessidade de se conceber instrumentos de avaliação capazes de retratar a essencialidade do jogo e de estabelecer uma conexão entre a avaliação do jogador e os conteúdos desenvolvidos no processo de ensino e treino (GRÉHAIGNE; GODBOUT, 1998; TENGA et al., 2009). Diante deste contexto, o presente artigo tem por objetivo fundamentar conceitualmente a construção de um modelo de avaliação dos comportamentos táticos desempenhados pelos jogadores de Futebol, com base nos princípios táticos fundamentais de jogo.

\section{Necessidade de confluência entre a especificidade do jogo e a estrutura do processo de ensino e treino no Futebol}

O Futebol se caracteriza pela existência simultânea de cooperação e oposição que a cada momento induz uma dinâmica relacional coletiva. A singularidade e a diversidade do fluxo de acontecimentos de jogo, que permitem a marcação de gols na baliza adversária e o seu impedimento na própria baliza, são construídas a partir das ações e das interações dos jogadores (JÚLIO; ARAÚJO, 2005). Para além dessas características, os constrangimentos gerados pelo acaso $^{1}$ (GARGANTA; CUNHA E SILVA, 2000) e as variáveis caóticas ${ }^{2}$ (LEBED, 2006) presentes no jogo também contribuem para a evolução da sua dinâmica e do seu resultado (WERNER, 1995).

Diante de todos esses atributos, pode-se considerar o jogo de Futebol como um macrosistema constituído por diferentes subsistemas (funcional, formal, organizacional, etc) que são influenciados e dependentes das condições de oposição, pressão temporal, adaptabilidade e cooperação (GARGANTA, 2001b). Nesse macrosistema as ações dos jogadores são integradas em uma estrutura que segue um determinado modelo, de acordo com certos princípios e regras que se concretizam em duas fases opostas, a saber, $\mathrm{o}$ ataque $\mathrm{e}$ a defesa (TEODORESCU, 1984).

No que respeita ao subsistema organizacional, admite-se que os jogadores devem ser capazes

\footnotetext{
1 O acaso é designado por "sorte» quando nos é favorável e por "azar» quando nos é desfavorável (EIGEN; WINKLER, 1989).

2 Variáveis caóticas são circunstâncias através das quais se pode atingir o objetivo (gol) de forma não planificada, casual ou imprevisível (LEBED, 2006).
} 
de reconhecer as variáveis de jogo (jogadores, bola, balizas, árbitros, demarcações físicas, etc.) e movimentarem-se em função de uma estratégia e organização tática coletiva. Acresce que o baixo número de ações realizadas pelos jogadores com a bola suscita que as capacidades táticas e os processos cognitivos subjacentes à tomada de decisão sejam frequentemente solicitados, uma vez que, as situações de jogo mudam constantemente ao longo do tempo e as ações necessitam ser continuamente geradas, recriadas e reconstruídas através da auto-organização da equipe (MCPHERSON, 1994).

Ao assumir essa necessidade de autoorganização coletiva, passa-se a entender que a preocupação dos jogadores de Futebol se centra, em larga medida, na gestão do espaço de jogo. Essa preocupação é legítima porque poderá exercer influência sobre outros componentes de jogo como o tempo, a tomada de decisão e a execução da ação (BUSCÀ; RIERA, 1999).

Desta forma, pode-se afirmar que, no plano coletivo, a equipe que estiver mais bem organizada e posicionada no campo de jogo ${ }^{3}$ terá melhores condições de conquistar os seus objetivos, já que poderá "manipular" a velocidade e a precisão das ações através da gestão do espaço de jogo. Isso significa que a equipe que conseguir coordenar as ações coletivas de ocupação dos espaços de jogo poderá reduzir o tempo de reação da equipe adversária em uma determinada situação, obrigando a que a mesma jogue em "crise de tempo", ou seja, diminuindoIhe a precisão nas ações. Esta conduz ao aumento dos erros cometidos pelos jogadores e, portanto, pela equipe, possibilitando a recuperação da posse de bola com maior facilidade. Subsequentemente, ao ter a posse de bola, a equipe que conseguir ampliar o espaço de jogo efetivo, terá maior probabilidade de chegar ao seu objetivo e, conseqüentemente, dificultará a tarefa de reconquista da bola pela equipe adversária.

Essa forma de conceber a dinâmica do jogo de Futebol confere destaque aos aspectos táticos que implicam na disposição e na movimentação efetiva dos jogadores no campo de jogo, com

\footnotetext{
${ }^{3}$ De acordo com Gréhaigne e Godbout (1995) a organização da equipe pode processar-se a dois níveis (de jogo e de equipe) e em função das suas características estruturais $e$ funcionais. Em relação ao nível de jogo ela se estabelece em função das relações de oposição e das linhas de força ofensiva e defensiva. Ao nível da equipe, ela se materializa por meio da distribuição formal dos jogadores no campo de jogo, de forma a permitir redes de comunicações e interações. Já em relação às características, enquanto as estruturais se associam a aspectos espaciais do campo de jogo, as funcionais reportam-se às trocas, regulações e reorganização dos elementos de jogo.
}

relação direta na unidade de movimentação da equipe, em função dos acontecimentos da partida, do modelo de jogo da equipe e da compreensão de jogo por parte dos jogadores.

Por sua vez, o processo de ensino e treino do Futebol deve tomar em conta essas características de forma a propiciar melhorias no desempenho dos jogadores e a proporcionar níveis superiores de organização coletiva. Para favorecer esse desenvolvimento torna-se fundamental que os jogadores consigam reconhecer com celeridade e facilidade as situações de jogo, no sentido de emitir respostas rápidas e eficazes as solicitações da partida (GRÉHAIGNE; GODBOUT; BOUTHIER, 1997).

Devido a essa necessidade de execução de respostas rápidas e eficazes, associada à impossibilidade de padronizar seqüências de ações, que podem ser utilizadas nas sessões de treino, parece ser importante e coerente que o processo de ensino e o treino do Futebol seja baseado em princípios de jogo. Os princípios de jogo decorrem da construção teórica a propósito da lógica do jogo e se operacionalizam nos comportamentos dos jogadores (CASTELO, 1994). Por isso, eles podem ser estabelecidos com base na dinâmica do jogo e em fatores relacionados ao rendimento individual e coletivo. Desta forma, faz todo sentido que o processo de ensino e treino tenha como orientação os princípios táticos do jogo de Futebol (HOLT; STREAN; BENGOECHEA, 2002).

A adoção de princípios táticos no processo de ensino e treino é importante porque proporciona aos jogadores a possibilidade de conseguirem soluções táticas eficazes para as situações de jogo (COSTA et al., 2009). Coletivamente, a forma e a dinâmica das interações desses princípios e as suas aplicações no contexto de jogo operacionalizam e caracterizam o modelo de jogo de cada equipe. Por esse motivo, o preceito do ensino e do treino baseado nos princípios táticos do Futebol revela implicações positivas para o desempenho do jogador e a organização da equipe. A transmissão e operacionalização dos conceitos, assim como o desenvolvimento da conscientização dos jogadores sobre esses princípios através do processo de ensino e treino, ajudam na seleção e na execução da ação tática necessária à situação de jogo (KIRK, 1983).

O desenvolvimento de tais princípios táticos no processo de ensino e no treino pode ser obtido por intermédio da alteração da estrutura formal e funcional do jogo (LEE; WARD, 2009). Através 
dessas alterações pode-se manipular a complexidade do jogo de acordo com 0 conhecimento tático dos praticantes e com os seus níveis de desempenho (MESQUITA, 2006). Isso acontece quando o treinador ou professor promove modificações na estrutura do exercício, sejam elas para facilitar o fluxo de jogo, designada de modificação por representação, ou para induzir a ocorrência de ações relacionadas com as capacidades táticas, denominada de representação por exagero (HOLT; STREAN; BENGOECHEA, 2002).

\section{Fundamentos da Avaliação do Comportamento Tático de Jogadores}

Segundo Veal (1993) as avaliações dos comportamentos dos jogadores geralmente ocorrem com base em testes que estão dissociados dos aspectos que retratam o sucesso no jogo. Por causa dessa incongruência, a principal desvantagem está associada à fraca relação dos seus resultados com a capacidade do praticante em realizar a ação no local certo e no tempo apropriado, quando confrontado com a idêntica situação no jogo.

Por esse motivo, pesquisadores têm referido que os instrumentos de avaliação do comportamento tático no Futebol devem procurar retratar os aspectos essenciais do jogo e do processo de ensino e treino, quando o objetivo desse processo é propiciar melhorias no desempenho dos jogadores (GRÉHAIGNE; GODBOUT, 1998; BLOMQVIST; VÄNTTINEN; LUHTANEN, 2005). Tentando apontar sugestões nesse caminho, Blomqvist, Vanttinen e Luhtanen (2005) sustentam que a avaliação realizada através do jogo é a forma mais válida de avaliar o conhecimento dos praticantes, onde 0 desempenho pode ser inferido por meio dos registros dos comportamentos apresentados durante o jogo e/ou através dos resultados das ações.

Essa forma de avaliação também tem sido advogada por outros pesquisadores que remetem para a importância da contextualização dos testes (ANASTASI, 1988; WIGGINS, 1993; OSLIN; MITCHELL; GRIFFIN, 1998). Segundo Anastasi (1988), a percepção de relevância do teste facilita a participação efetiva dos praticantes e influencia a qualidade da informação, uma vez que os avaliados estão empenhados em demonstrar o seu repertório de habilidades.
Ao ter em conta essas necessidades de retratação da especificidade do jogo e da conexão da avaliação com os conteúdos desenvolvidos no processo de ensino e treino, afigura-se plausível afirmar que os instrumentos de avaliação no Futebol devem assumir um caráter mais heurístico, de forma a suprir as exigências e conseguir retratar $o$ desenvolvimento e o desempenho do jogador no jogo (TENGA et al., 2009). Adicionalmente a essa característica, Gréhaigne, Godbout e Bouthier (1997) destacam a importância da objetividade da medida, de forma que 0 teste consiga manter a sua capacidade de avaliação a partir do contexto de jogo.

\section{Proposta de Avaliação do Comportamento Tático no Futebol baseada nos Princípios Táticos Fundamentais de jogo}

A partir do conjunto de sugestõe
apresentadas pela literatura em relação à concessão de instrumentos de avaliação, admitese que a inclusão dos princípios táticos de jogo, em instrumentos de avaliação do comportamento tático do jogador no Futebol, comporta benefícios no que refere à especificidade do jogo, à avaliação do desempenho do praticante em contexto de jogo, à sintonia com conteúdos desenvolvidos no processo de treino, à objetividade da medida, à consideração da oposição e à avaliação de jogadores de diferentes níveis de formação.

Com base nessas considerações, sugere-se que a avaliação dos comportamentos táticos dos jogadores de Futebol tenha como variáveis latentes ${ }^{4}$ os dez princípios táticos fundamentais da fase ofensiva e defensiva ${ }^{5}$ que são apresentados no Quadro 1. A contemplação de todos esses princípios fundamentais na avaliação do comportamento tático dos jogadores Futebol se justifica devido às suas normatizações e referências espaciais permitirem aos jogadores a gestão de todo o espaço de jogo, tanto para a fase ofensiva, quanto para a fase defensiva (vide Figura 1).

\footnotetext{
${ }^{4}$ Para Pasquali (2007), a variável latente está relacionada ao constructo do teste e se posiciona como o objeto que o teste guer medir.

5 Mais informações sobre as definições e aplicações dos princípios táticos fundamentais do jogo de Futebol podem ser obtidas no trabalho publicado por Costa et al. (2009). Princípios Táticos do Jogo de Futebol: conceitos e aplicação. Revista Motriz, 15(3), 657-668.
} 
Quadro 1. Categorias, sub-categorias, variáveis latentes e definições utilizadas para a avaliação do comportamento tático de jogadores de Futebol.

\begin{tabular}{|c|c|c|c|}
\hline Categoria & Sub-categorias & Variáveis Latentes & Definições \\
\hline \multirow{10}{*}{$\begin{array}{l}\text { Princípios } \\
\text { Táticos } \\
\text { Fundamentais } \\
\text { do Jogo de } \\
\text { Futebol }\end{array}$} & \multirow{5}{*}{ Ofensivo } & Penetração & $\begin{array}{l}\text { Redução da distância entre o portador da bola e a baliza ou a linha } \\
\text { de fundo adversária. }\end{array}$ \\
\hline & & Cobertura Ofensiva & Oferecimento de apoios ofensivos ao portador da bola. \\
\hline & & Mobilidade & Criação de instabilidade na organização defensiva adversária. \\
\hline & & Espaço & $\begin{array}{l}\text { Utilização e ampliação do espaço de jogo efetivo em largura e } \\
\text { profundidade. }\end{array}$ \\
\hline & & Unidade Ofensiva & $\begin{array}{l}\text { Movimentação de avanço ou apoio ofensivo do(s) jogador(es) que } \\
\text { compõe }(\mathrm{m}) \mathrm{a}(\mathrm{s}) \text { última(s) linha (s) transversais da equipe. }\end{array}$ \\
\hline & \multirow{5}{*}{ Defensivo } & Contenção & Realização de oposição ao portador da bola. \\
\hline & & Cobertura Defensiva & Oferecimento de apoios defensivos ao jogador de contenção. \\
\hline & & Equilíbrio & Estabilidade ou superioridade numérica nas relações de oposição. \\
\hline & & Concentração & Aumento de proteção defensiva na zona de maior risco à baliza. \\
\hline & & Unidade Defensiva & Redução do espaço de jogo efetivo da equipe adversária. \\
\hline
\end{tabular}
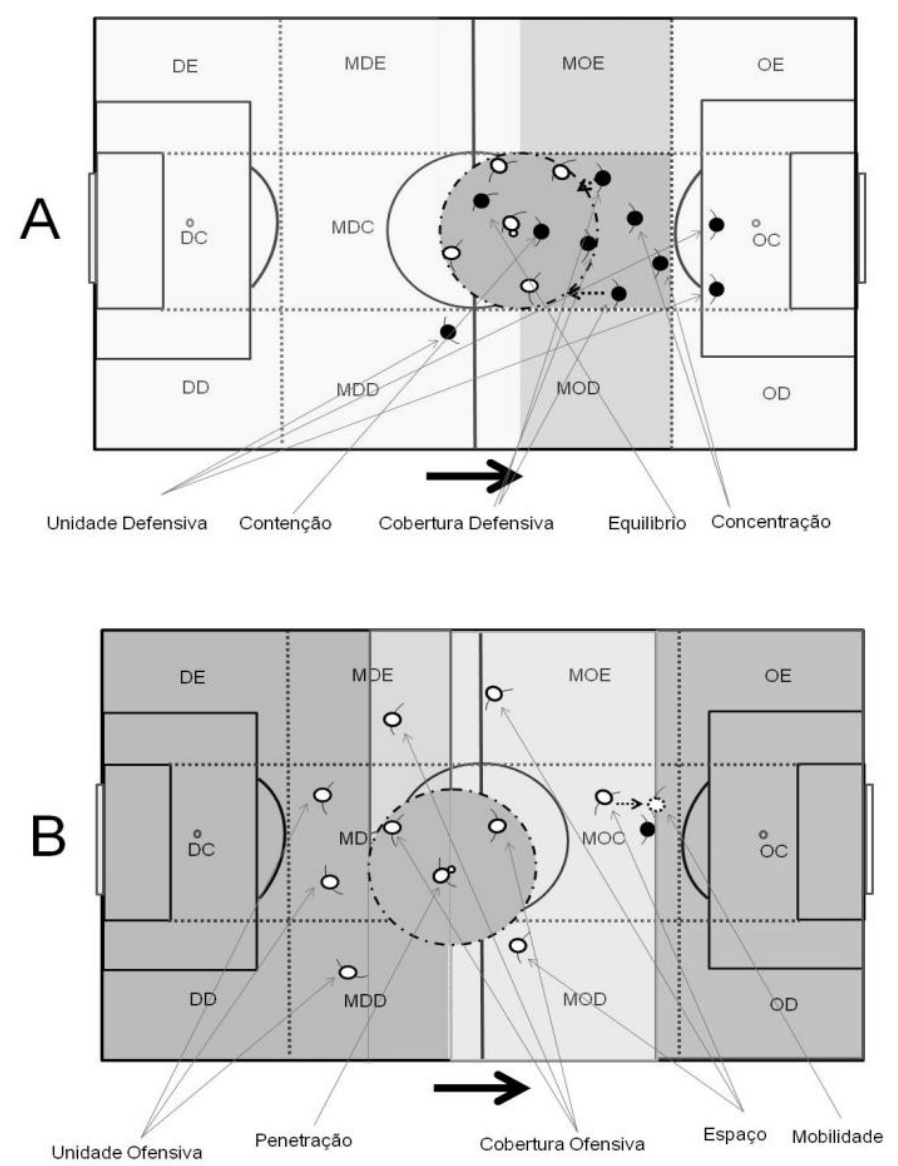

Figura 1. Princípios Táticos Fundamentais do jogo de Futebol em função das fases (A - defensiva e B ofensiva) e da gestão do espaço de jogo. 
Quadro 2. Categorias, sub-categorias, variáveis latentes e variáveis observadas relacionados aos Princípios Táticos Fundamentais do Futebol.

\begin{tabular}{|c|c|c|c|}
\hline Categorias & $\begin{array}{c}\text { Sub- } \\
\text { categorias }\end{array}$ & $\begin{array}{l}\text { Variáveis } \\
\text { Latentes }\end{array}$ & Variáveis Observadas \\
\hline & \multirow{4}{*}{ Ofensivo } & Penetração & $\begin{array}{l}\text { Condução da bola pelo espaço disponível (com ou sem defensores à frente). } \\
\text { Realização de dribles que colocam a equipe em superioridade numérica em ações de } \\
\text { ataque. } \\
\text { Condução de bola em direção à linha de fundo ou ao gol adversário. } \\
\text { Realização de dribles que propiciam condições favoráveis a um passe/assistência para o } \\
\text { companheiro dar seqüência ao jogo. }\end{array}$ \\
\hline & & Espaço & $\begin{array}{l}\text { Procura de espaços não ocupados pelos adversários no campo de jogo. } \\
\text { Movimentações de ampliação do espaço de jogo que proporcionam superioridade } \\
\text { numérica no ataque. } \\
\text { Drible ou condução para trás/linha lateral que permitem diminuir a pressão adversária } \\
\text { sobre a bola. } \\
\text { Movimentações que permitem (re)iniciar o processo ofensivo em zonas distantes daquela } \\
\text { onde ocorreu a recuperação da posse de bola. }\end{array}$ \\
\hline & & Mobilidade & $\begin{array}{l}\text { Movimentações em profundidade ou em largura, "nas costas" do último defensor em } \\
\text { direção a linha de fundo ou ao gol adversário. } \\
\text { Movimentações em profundidade ou em largura, "nas costas" do último defensor que } \\
\text { visem ganho de espaço ofensivo. } \\
\text { Movimentações em profundidade ou em largura, "nas costas" do último defensor que } \\
\text { propiciem receber a bola. } \\
\text { Movimentações em profundidade ou em largura, "nas costas" do último defensor que } \\
\text { visem a criação de oportunidades para a sequência ofensiva do jogo. }\end{array}$ \\
\hline Princípios & & $\begin{array}{l}\text { Unidade } \\
\text { Ofensiva }\end{array}$ & $\begin{array}{l}\text { Avanço da última linha de defesa permitindo que a equipe jogue em bloco. } \\
\text { Saída da última linha de defesa dos setores defensivos e aproximação da mesma à linha } \\
\text { de meio-campo. } \\
\text { Avanço dos jogadores da defesa propiciando que mais companheiros participem das } \\
\text { ações no centro de jogo. }\end{array}$ \\
\hline
\end{tabular}

Táticos

Marcação ao portador da bola, impedindo a ação de penetração.

$\begin{array}{ll} & \text { Ação de "proteção da bola" que impede o adversário de alcançá-la. } \\ \text { Contenção } & \text { Realização da "dobra" defensiva ao portador da bola. }\end{array}$

Realização de faltas técnicas para conter a progressão da equipe adversária, quando o sistema defensivo está desorganizado.

Ação de cobertura ao jogador de contenção.

Posicionamento que permite obstruir eventuais linhas de passe para jogadores

$\begin{array}{ll}\text { Cobertura } & \text { adversários. } \\ \text { Marcação de adversário(s) que pode }(\mathrm{m}) \text { receber a bola em situações vantajosas para o }\end{array}$ Defensiva ataque.

Posicionamento adequado que permite marcar o portador da bola sempre que o jogador de contenção for driblado.

Movimentações que permitem assegurar estabilidade defensiva.

Defensivo Equilíbrio $\quad$ Movimentação de recuperação defensiva feita por trás da linha da bola.

Marcação de jogadores adversários que apoiam as ações ofensivas do portador da bola.

Movimentação que propicia reforço defensivo na zona de maior perigo para a equipe. Marcação de jogadores adversários que buscam aumentar o espaço de jogo ofensivo.

Concentração Movimentações que propiciam aumento do número de jogadores entre a bola e o gol. Movimentações que condicionam as ações de ataque da equipe adversária para as extremidades do campo de jogo.

Organização dos posicionamentos defensivos após perda da posse de bola, com o objetivo de reorganizar as linhas de defesa.

Movimentação dos jogadores, principalmente laterais e extremos, em direção ao corredor

Unidade central quando as ações do jogo são desenvolvidas no lado oposto.

Defensiva Compactação defensiva da equipe na zona do campo de jogo que representa perigo maior perigo à baliza.

Movimentação dos jogadores que compõem a última linha de defesa de forma a reduzir o campo de jogo do adversário (utilizando o recurso da lei do impedimento).

A partir da conjunção entre a operacionalização dos princípios fundamentais do jogo de Futebol e a gestão do espaço de jogo, algumas ações táticas podem ser observadas no jogo e descritas, permitindo que tais princípios sejam identificados e possam fazer parte da avaliação do comportamento tático do jogador de Futebol. O Quadro 2 mostra, em função das categorias, sub-categorias e variáveis latentes, quais ações táticas podem ser consideradas como variáveis observadas em situações de jogo. 
Quadro 3. Categorias, sub-categorias, variáveis latentes e variáveis observadas relacionados à Localização e ao Resultado da ação tática

\begin{tabular}{|c|c|c|c|}
\hline Categorias & Sub-categorias & Variáveis Latentes & Variáveis Observadas \\
\hline \multirow{4}{*}{$\begin{array}{l}\text { Localização da ação } \\
\text { no Campo de Jogo }\end{array}$} & \multirow{2}{*}{ Ofensivo } & \multirow{2}{*}{ Meio Campo Ofensivo } & Ações Táticas Ofensivas \\
\hline & & & Ações Táticas Defensivas \\
\hline & \multirow{2}{*}{ Defensivo } & \multirow{2}{*}{ Meio Campo Defensivo } & Ações Táticas Ofensivas \\
\hline & & & Ações Táticas Defensivas \\
\hline \multirow{10}{*}{ Resultado da Ação } & \multirow{5}{*}{ Ofensiva } & \multirow{5}{*}{ Eficácia Ofensiva } & Realizar finalização ao gol \\
\hline & & & Continuar com a posse de bola \\
\hline & & & Sofrer falta, ganhar lateral ou escanteio \\
\hline & & & Cometer falta, ceder lateral ou escanteio \\
\hline & & & Perder a posse de bola \\
\hline & \multirow{5}{*}{ Defensiva } & \multirow{5}{*}{ Eficácia Defensiva } & Recuperar a posse de bola \\
\hline & & & Sofrer falta, ganhar lateral ou escanteio \\
\hline & & & Cometer falta, ceder lateral ou escanteio \\
\hline & & & Continuar sem a posse de bola \\
\hline & & & Sofrer finalização ao gol \\
\hline
\end{tabular}

$\mathrm{Na}$ justa medida que o comportamento dos jogadores se adequada às sucessivas alterações produzidas no jogo ou no treino, alguns indicadores de desempenho $0^{6}$ também podem ser concebidos, na tentativa de ponderar e compreender a eficiência ${ }^{7}$ e a eficácia das respostas em função das exigências da situação. Os indicadores de desempenho para as ações táticas características dos princípios táticos fundamentais do jogo de Futebol foram descritos e podem ser consultadas no Anexo 1. Estes indicadores contribuem para a compreensão da eficiência de realização da ação tática, assim como as informações qualitativas advindas da sua localização no campo de jogo podem fornecer informação adicional sobre a eficiência do comportamento desempenhado pelo jogador (vide Quadro 3). No que refere à eficácia do comportamento, dez possibilidades de resultados foram organizadas em função das fases de jogo e dos seus objetivos e foram apresentadas no Quadro 3. Essas possibilidades compreendem as variáveis observadas em função das suas categorias, sub-categorias e variáveis latentes que compõem o instrumento de avaliação do comportamento tático do jogador de Futebol.

\section{Considerações Finais}

O objetivo desse trabalho conflui na proposta de novas categorias e variáveis baseadas nos

\footnotetext{
${ }^{6}$ De acordo com Hughes e Bartlett (2002) um indicador de performance é uma seleção ou combinação de variáveis de ação que objetivam definir alguns ou todos os aspectos da performance.
}

Motriz, Rio Claro, v.17, n.3, p.511-524, jul./set. 2011 princípios táticos fundamentais do jogo de Futebol para a avaliação dos comportamentos dos jogadores (WORTHINGTON, 1974; QUEIROZ, 1983; CASTELO, 1994). Esse conceito visa atender a demanda por um instrumento específico e voltado para o processo de ensino e treino do Futebol (GRÉHAIGNE; GODBOUT, 1998; BLOMQVIST; VÄNTTINEN; LUHTANEN, 2005). Adicionalmente, a adoção dessa proposta também poderá ser útil para complementar outros tipos de avaliações de desempenho de jogadores que estão focadas nos aspectos técnicos e fisiológicos (TESSITORE et al., 2006; JONES; DRUST, 2007; KELLY; DRUST, 2009) ou nos eventos de jogo (TAYLOR; MELLALIEU; JAMES, 2005; FRENCKEN; LEMMINK, 2009).

Acresce que as categorias e variáveis presentes na proposta aqui apresentada têm também por objetivo suprir algumas das limitações evidenciadas pela literatura para os instrumentos de avaliação do comportamento tático, nomeadamente: a avaliação integrada do jogador ao contexto de jogo (BLOMQVIST; VÄNTTINEN; LUHTANEN, 2005), a consideração da interação dos oponentes (TENGA et al., 2009), a capacidade de avaliação do progresso do praticante durante vários estágios do período de formação (MEMMERT, 2002) e a conexão com os conteúdos ministrados no processo de ensino e treino (GRÉHAIGNE; GODBOUT, 1998).

\footnotetext{
7 Segundo Mesquita (1998) o conceito de eficiência está relacionado com a execução do movimento e o conceito de eficácia com resultado obtido.
} 
Especificamente, a capacidade de estabelecer conexão com os conteúdos ministrados nas sessões de treino afigura-se importante, uma vez que estudos realizados recentemente têm evidenciado diferenças de conhecimento tático e de tomada de decisão entre os jogadores para as situações de jogo com a posse de bola e para as situações de jogo sem a posse de bola (BLOMQVIST; VÄNTTINEN; LUHTANEN, 2005; LEE; WARD, 2009).

A pesquisa realizada por Blomqvist, Vänttinen e Luhtanen (2005) mostrou que os resultados de conhecimento tático e de tomada de decisão dos jogadores em situações com a posse de bola foram superiores aos resultados obtidos pelos jogadores em situações sem a posse de bola. Em função destes resultados os pesquisadores argumentaram que parecia haver uma focalização do processo de ensino e treino no desenvolvimento de habilidades específicas para as situações que se desenvolvem em contato com a bola e que o ensino dos movimentos sem bola era muito raro durante as sessões de treino.

Lee e Ward (2009) também destacaram essa debilidade no ensino da tática ao afirmarem que as sessões de treino parecem estar mais focadas no ensino dos aspectos gerais da tática em detrimento dos específicos. Em adição, esses pesquisadores se reportaram à importância da avaliação do comportamento do jogador ser realizada "in loco", reforçando a importância ecológica dos instrumentos de avaliação, isto é, da sua desejável afinidade com os conteúdos ministrados nas sessões de treino.

Diante desta constatação parece plausível inferir que o acesso a instrumentos de avaliação que permitam registrar resultados fidedignos sobre o comportamento tático e a progressão dos praticantes pode permitir a valorização do processo de ensino e treino. Além disso, a existência de instrumentos dessa natureza potencializaria a realização de avaliações periódicas e permitiria aos professores/treinadores a focalização dos conteúdos das sessões de treino no desenvolvimento dos comportamentos táticos necessários para a formação do praticante.

Outro aspecto importante a referir diz respeito à flexibilidade de utilização das categorias e variáveis que compõem a proposta aqui apresentada. Segundo Oslin, Mitchell e Griffin (1998) esse é um aspecto positivo e importante a ser considerado em instrumentos dessa natureza, porque permite aos pesquisadores, treinadores e/ou professores a sua utilização, tanto em situações de avaliações "in loco" como em situações de avaliações por videotapes. Além disso, a utilização de algumas ou de todas as categorias do instrumento também é válida para avaliar os comportamentos desempenhados pelos jogadores, consoante os conteúdos desenvolvidos nos treinos, os critérios de desempenho estabelecidos pelo professor/treinador e os objetivos da avaliação.

Por apresentar essas vantagens, a avaliação baseada nos princípios táticos fundamentais do jogo de Futebol pode auxiliar os professores e treinadores a melhorar e adequar a capacidade de diagnóstico, presunção e avaliação da orientação didático-metodológica conferida no processo de ensino e treino. Além do mais, esse tipo de instrumento permite a esses profissionais avaliarem jogadores em diferentes equipes e categorias, proporcionando a emergência de ilações sobre o modelo de jogo adotado por cada uma delas a partir da dinâmica de interação dos princípios táticos de jogo expressados nas ações desempenhadas pelos jogadores.

Essa proposta visa ainda reduzir a subjetividade implícita nos indicadores de desempenho presentes em outros instrumentos de avaliação do comportamento tático, especialmente no que concerne a avaliação do jogador sem a posse de bola (MEMMERT; HARVEY, 2008). A adoção dos dez princípios fundamentais do jogo de Futebol permite maior especificidade na observação e identificação das ações táticas desempenhadas pelos jogadores no campo de jogo, uma vez que a sua normatização e referências espaciais permitem a identificação objetiva de todas as variáveis táticas relacionadas com a gestão do espaço de jogo feita pelos jogadores.

Por pretender ser objetiva e rigorosa esta proposta de avaliação também pode propiciar maior fiabilidade nas avaliações que, por ventura, sejam feitas por pares ou realizadas em períodos temporais distintos. Essa é uma característica importante para um instrumento que permite realizar avaliações longitudinais, uma vez que 0 uso sistemático de avaliações ajuda a aumentar o controle e o conhecimento sobre o processo de ensino e o desenvolvimento do praticante (RICHARD; GODBOUT; GRIFFIN, 2002). Por sua 
vez, esse controle auxilia na obtenção de informações para a orientação metodológica do processo de ensino e treino, permitindo (i) a planificação e a organização do treino com maior especificidade atendendo a natureza das tarefas; (ii) a regulação da aprendizagem dos comportamentos tático-técnicos de acordo com a dinâmica das interações dos princípios táticos e o modelo de jogo da equipe; e (iii) a interpretação da organização das equipes e das ações que concorrem para a qualidade do jogo (GARGANTA, 2001a). Em adição, essa proposta também pode auxiliar os praticantes no desenvolvimento dos seus conhecimentos e comportamentos, aumentando as suas capacidades em reconhecer as situações de jogo e ajudando na transferência do seu aprendizado para os contextos que exijam tomada de decisão e execução motora condizentes com os problemas típicos e atípicos do jogo.

Em síntese, pretende-se que a proposta de inclusão dos dez princípios táticos fundamentais do jogo de Futebol, em instrumentos de avaliação do comportamento tático de jogadores, se afigure pertinente e útil para ser utilizada no processo de ensino e treino Tal pode ser justificado pelo fato dos seus atributos e contributos terem em conta: (i) a especificidade da modalidade; (ii) a avaliação integrada do jogador ao contexto de jogo; (iii) a presença do adversário; (iv) a redução da subjetividade das medidas; (v) a conexão com os conteúdos ministrados no treino; e (vi) a avaliação do progresso dos jogadores em todas as categorias de formação.

\section{Referências}

ANASTASI, A. Psychological testing. New York: Macmillan. 1988.

BARD, C.; FLEURY, M. Analysis of visual search activity during sport problem situation. Journal of Human Movement Studies, Edinburgo, v. 3, p. 214-222, 1976.

BLOMQVIST, M.; VÄNTTINEN, T.; LUHTANEN, P. Assessment of secondary school students' decision-making and game-play ability in soccer. Physical Education \& Sport Pedagogy, Londres, v. 10, n. 2, p. 107-119, 2005.

BUSCA, B.; RIERA, J. Orientación deportiva hacia actividades tácticas. Revista de Psicologia del Deporte, Barcelona, v. 8, n. 2, p. 271-276, 1999.

CASTELO, J. Futebol modelo técnico-táctico do jogo: identificação e caracterização das grandes tendências evolutivas das equipas de rendimento superior. Lisboa: Faculdade de Motricidade Humana. 1994.

COSTA, I. T. et al. Princípios táticos do jogo de futebol: conceitos e aplicação. Revista Motriz, Rio Claro, v. 15, n. 3, p. 657-668, 2009.

EIGEN, M.; WINKLER, R. O Jogo: as leis naturais que regulam o acaso. Lisboa: Gradiva, 1989.

FRENCH, K.; THOMAS, J. The relation of knowledge development to children's basketball performance. Journal of Sport Psychology, Nova lorque, v. 9, p. 15-32, 1987.

FRENCKEN, W. G. P.; LEMMINK, K. A. Team kinematics of small-sided soccer games. In: WORLD CONGRESS OF SCIENCE AND FOOTBALL, 6., 2009, London. Proceedings... London: Routledge, 2009, p. 167-172.

GARGANTA, J. Futebol e ciência. Ciência e Futebol. Lecturas en Educación Física y Deportes, Buenos Aires, v. 7, n. 40, 2001a. Disponível em: <http://www.efdeportes.com>. Acesso em: 30 jul. 2008

GARGANTA, J. Tactical modelling in soccer: a critical view. In: WORLD CONGRESS OF NATIONAL ANALYSIS OF SPORT, 4., 2001, Porto. Proceedings... Porto: Faculdade de Desporto da Universidade do Porto, 2001b, p. 3340.

GARGANTA, J.; CUNHA E SILVA, P. O jogo de futebol: entre o caos e a regra. Horizonte Revista de Educação Física e Desporto, Lisboa, v. 16, n. 91, p. 5-8, 2000.

GRÉHAIGNE, J. F.; GODBOUT, P. Tactical knowledge in team sports from a constructivist and cognitivist perspective. Quest, Nova lorque, v. 47 , n. 4 , p. 490-505, 1995.

GRÉHAIGNE, J. F.; GODBOUT, P. Formative assessment in team sports in a tactical approach context. Joperd, Reston, v. 69, n. 1, p. 46-51, 1998.

GRÉHAIGNE, J.; GODBOUT, P.; BOUTHIER, D. Performance assesment in team sports. Journal of Teaching in Physical Education, Champaign, v. 16, p. 500-516, 1997.

HOLT, N. L.; STREAN, W. B.; BENGOECHEA, E. G. Expanding the teaching games for understanding model: new avenues for future research and practice. Journal of Teaching in Physical Education, Champaign, v. 21, p. 162176, 2002. 
HUGHES, M. D.; BARTLETT, R. M. The use of performance indicators in performance analysis. Journal of Sports Sciences, Londres, v. 20, n. 10, p. 739-754, 2002.

JONES, S.; DRUST, B. Physiological and technical demands of $4 \vee 4$ and $8 v 8$ games in elite youth soccer players. Kinesiology, Londres, v. 39, n. 2, p. 150-156, 2007.

JÚLIO, L.; ARAÚJO, D. Abordagem dinâmica da acção táctica no jogo de futebol. In: ARAÚJO, D. (Ed.). O contexto da decisão: a acção táctica do desporto. Lisboa: Visão e Contextos, 2005. p. 159-178.

KELLY, D. M.; DRUST, B. The effect of pitch dimensions on heart rate responses and technical demands of small-sided soccer games in elite players. Journal of Science and Medicine in Sport, Nova lorque, v. 12, p. 475-479, 2009.

KIRK, D. Theoretical guidelines for teaching games for understanding. Bulletin of Physical Education, Driffield, v. 19, n. 1, p. 41-45, 1983.

KIRKHART, M. W. The nature of declarative and nondeclarative knowledge for implicit and explicit learning. Journal of General Psychology, Filadélfia, v. 128, n. 4, p. 447-461, 2001.

LEBED, F. System approach to games and competitive playing. European Journal of Sport Science, Londres, v. 6, n. 1, p. 33-42, 2006.

LEE, M. A.; WARD, P. Generalization of tactics in tag rugby from practice to games in middle school physical education. Physical Education \& Sport Pedagogy, Londres, v. 14, n. 2, p. 189-207, 2009.

MANGAS, C.; GARGANTA, J.; FONSECA, A. Estudo comparativo do conhecimento declarativo de jovens praticantes de futebol em função do seu nível competitivo. In: JANEIRA, M. A.; BRANDÃO, E. (Eds.). Estudos 3. Cidade do Porto: Saúde e Sá, 2002. p. 25-32.

MCPHERSON, S. The development of sport expertise: mapping the tactical domain. Quest, Nova lorque, v. 46, n. 2, p. 223-240, 1994.

\section{MEMMERT, D. Diagnostik Taktischer} Leistungskomponenten: Spieltestsituationen und Konzeptorientierte Expertenratings. 2002. 276 f. Tese (Doutorado em Ciências do Esporte) Universidade de Heidelberg, Alemanha, 2002.

MEMMERT, D.; HARVEY, S. The game performance assessment instrument (GPAI): some concerns and solutions for further development. Journal of Teaching in Physical Education, Champaign, v. 27, n. 2, p. 220-240, 2008.
MESQUITA, I. The multidimensionality in the domain of the volleyball skills. In: WORLD CONGRESS OF NARIONAL ANALYSIS OF SPORT, 4., 1998, Porto. Proceedings... Porto, Portugal: Multitema, 1998. p. 147-155.

MESQUITA, I. Ensinar bem para aprender melhor o jogo de voleibol. In: TANI, G.; BENTO J.; PETERSEN, R. (Eds.). Pedagogia do desporto. Rio de Janeiro: Guanabara Koogan, 2006. p. 327343.

OSLIN, J. L.; MITCHELL, S. A.; GRIFFIN, L. L. The game performance assessment instrument (GPAI): development and preliminary validation. Journal of Teaching in Physical Education, Champaign, v. 17, n. 2, p. 231-243, 1998.

PASQUALI, L. Validade dos testes psicológicos: derá possível reencontrar o caminho?

Psicologia: Teoria e Pesquisa, Brasília, v. 23, ed. especial, p. 99-107, 2007.

QUEIROZ, C. M. Para uma teoria de ensino/treino do futebol. Ludens, Lisboa, v. 8, n. 1, p. 25-44, 1983.

RICHARD, J. F.; GODBOUT, P.; GRIFFIN, L. L. Assessing game performance; an introduction to the team sport assessment procedure (TSAP). Physical and Health Education Journal, Nova lorque, v. 68, n. 1, p. 12-18, 2002.

TAYLOR, J. B.; MELLALIEU, S. D.; JAMES, N. A Comparison of Individual and unit tactical behaviour and team strategy in professional soccer. International Journal of Performance Analysis in Sport, Cardiff, v. 5, p. 87-101, 2005.

TENENBAUM, G.; LIDOR, R. Research on decision-making and the use of cognitive strategies in sport settings. In: HACKFORT, D.; DUDA, J.; LIDOR R. (Eds.). Handbook of research in applied sport and exercise psychology: international perspectives. Morgantown: WV, 2005. p. 75-91.

TENGA, A. et al. Developing a new method for team match performance analysis in professional soccer and testing its reliability. International Journal of Performance Analysis of Sport, Cardiff, v. 9, p. 8-25, 2009.

\section{TEODORESCU, L. Problemas de teoria e metodologia nos jogos desportivos. Lisboa: Livros Horizontes, 1984.}

TESSITORE, A. et al. Physiological and technical aspects of "6-a-side" soccer drills. Journal of Sports Medicine Physical Fitness, Torino, v. 46, p. 36-43, 2006. 
VEAL, M. The role of assessment and evaluation in secondary physical education: a pedagogical view. In: RINK, E. J. (Ed.). Critical crossroads: middle and secondary school physical education. Reston, VA: National Association for Sport and Physical Education, 1993. p. 93-99.

WERNER, S. El duelo entre dos: libro de ejercicios de uno contra uno. Barcelona: Paidotribo. 1995.

WIGGINS, G. Assessing student performance: exploring the purpose and limits of testing. São Francisco, CA: Jossey-Bass. 1993.

WILLIAMS, M.; DAVIDS, K. Declarative knowledge in sport: a by-product of experience or a characteristic of expertise? Journal of Sport \& Exercise Psychology, Nova lorque, v. 17, n. 3, p. 259-275, 1995.

WORTHINGTON, E. Learning \& teaching soccer skills. Califórnia: Hal Leighton Printing Company, 1974.

Apoio: Programa AlBan, Programa de bolsas de alto nível da União Europeia para América Latina, bolsa no E07D400279BR.

\section{Endereço:}

Israel Teoldo da Costa

DEF-Universidade Federal de Viçosa

Av. PH Rolfs, $s / n$ - Campus Universitário

Viçosa MG Brasil

36570-000

Telefone: (031) 3899.4394

Fax: (31) 3899.2249

e-mail: israel.teoldo@ufv.br

Recebido em: 10 de dezembro de 2009.

Aceito em: 21 de julho de 2011.

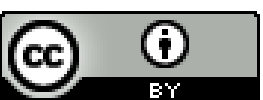

Motriz. Revista de Educação Física. UNESP, Rio Claro, SP, Brasil - elSSN: 1980-6574 - está licenciada sob Creative Commons - Atribuição 3.0 
Anexo 1: Indicadores de desempenho dos Princípios Táticos Fundamentais do jogo de Futebol.

\section{Penetração \\ Indicadores de Desempenho}

Bem sucedida $(+)$

a-Propiciar remate, passe ou drible.

Mal sucedida (-)

a-Permite o desarme adversário / b-Dirigir jogo espaço ocupado.

Descrição dos Indicadores de Desempenho

Bem sucedida $(+)$

a-Quando a movimentação do portador da bola propicia um remate, um passe ou um drible (ofensivo).

Mal sucedida (-)

a-Quando a movimentação do portador da bola permite ao adversário desarmá-lo.

b-Quando o portador da bola se dirige para um espaço já ocupado por outros jogadores, dificultando a ação ofensiva da própria equipe.

\section{Cobertura Ofensiva}

\section{Indicadores de Desempenho}

Bem sucedida $(+)$

a-Garantir linha de passe / b-Reduzir pressão portador / c-Permite possibilidade de remate.

Mal sucedida (-)

a-Não garantir linha de passe / b-Não reduzir pressão portador / c-Não permite possibilidade de remate.

Descrição dos Indicadores

Bem sucedida $(+)$

a-Quando a movimentação do jogador garante linha de passe ao portador da bola.

b-Quando a movimentação do jogador propicia a redução do número de adversários sobre o portador da bola.

c-Quando a movimentação do jogador permite possibilidade de remate, a partir de ações originadas na linha de fundo.

Mal sucedida (-)

a-Quando a movimentação do jogador não garante linha de passe ao portador da bola.

b-Quando a movimentação do jogador não propicia a redução do número de adversários sobre o portador da bola.

c-Quando a movimentação do jogador não permite possibilidade de remate, a partir de ações originadas na linha de fundo.

\section{Espaço}

Indicadores de Desempenho

Bem sucedida (+)

a-Ampliar largura EJE / b-Ampliar profundidade EJE / c-Criar espaços para movimentação dos colegas de equipe / d-Ir para pontos menor pressão / e-Diminuir pressão (lado ou atrás do CJ) / f-Manter a posse de bola.

Mal sucedida (-)

a-Não ampliar largura EJE / b-Não ampliar profundidade EJE / c-Não criar espaços para movimentação dos colegas de equipe / d-Não ir p/pontos menor pressão / e-Não diminuir pressão (lado ou atrás do CJ) / f-Permite o desarme adversário.

Descrição dos Indicadores

Bem sucedida $(+)$

a-Quando a movimentação do jogador propicia ampliação do espaço de jogo em largura da sua equipe, isto é, amplia o limite transversal do espaço de jogo efetivo.

b-Quando a movimentação do jogador propicia ampliação do espaço de jogo em profundidade até a linha do último jogador de defesa isto é, amplia o limite longitudinal do espaço de jogo efetivo.

c-Quando a movimentação do jogador (mesmo para zona de maior pressão) propicia a criação de espaços para a movimentação de outros jogadores da sua equipe ou um passe de sucesso.

d-Quando a movimentação do jogador lhe permite posicionar-se em pontos de menor pressão adversária (dentro do espaço de jogo efetivo).

e-Quando a movimentação do portador da bola (deslocamentos laterais ou para trás) propicia redução de pressão sobre a bola e assegura condições para dar sequência à ação ofensiva.

f-Quando a movimentação do portador da bola (deslocamentos laterais ou para trás) permite que a equipe mantenha a posse de bola. Mal sucedida (-)

a-Quando a movimentação do jogador não propicia ampliação do espaço de jogo em largura da sua equipe, isto é, não amplia o limite transversal do espaço de jogo efetivo.

b-Quando a movimentação do jogador não propicia ampliação do espaço de jogo em profundidade até a linha do último jogador de defesa, isto é, não amplia o limite longitudinal do espaço de jogo efetivo.

c-Quando a movimentação do jogador (mesmo para zona de maior pressão) não propicia criação de espaços para a movimentação de outros jogadores da sua equipe ou um passe de sucesso.

d-Quando a movimentação do jogador não lhe permite posicionar em pontos de menor pressão adversária (dentro do espaço de jogo efetivo).

e-Quando a movimentação do jogador (deslocamentos laterais ou para trás) não propicia redução de pressão sobre a bola nem assegura condições para dar sequência à ação ofensiva.

f-Quando a movimentação do portador da bola permite um desarme por parte do adversário.

\section{Mobilidade}

Indicadores de Desempenho

Bem sucedida $(+)$

a-Possibilitar passe profundidade para colega / b- Amplia EJE "nas costas" da defesa.

Mal sucedida (-)

a-Não possibilitar passe profundidade para colega / b-Jogador fica em impedimento.

Descrição dos Indicadores

Bem sucedida $(+)$

a-Quando a movimentação do jogador cria ao portador da bola a possibilidade de passe em profundidade para um colega em ações de ruptura em relação à defesa adversária.

b-Quando a movimentação do jogador possibilita o aumento do espaço de jogo efetivo da equipe "nas costas" da última linha de defesa. 
Anexo 1: continuação

\section{Mobilidade (cont.)}

Mal sucedida (-)

a-Quando a movimentação do jogador não cria ao portador da bola a possibilidade de passe em profundidade para um colega em ações de ruptura em relação à última linha de defesa adversária.

b-Quando a movimentação do jogador o coloca em situação de impedimento.

\section{Unidade Ofensiva}

\section{Indicadores de Desempenho}

Bem sucedida (+)

a-Aproximar a equipe ao CJ / b-Participar na ação subsequente / c-Contribuir p/ações ofensivas atrás da linha da bola / d-Auxiliar a equipe avançar ao MCO.

Mal sucedida (-)

a-Não aproximar a equipe ao CJ / b-Não participar na ação subsequente / c-Não contribuir p/ações ofensivas atrás da linha da bola / d-

Não auxiliar a equipe avançar ao MCO.

Descrição dos Indicadores

Bem sucedida $(+)$

a-Quando a movimentação do jogador permite que outros companheiros participem das ações da equipe ou se aproximem do centro de jogo.

b- Quando a movimentação do jogador lhe faculta a possibilidade de participar de uma ação ofensiva/defensiva subsequente.

c- Quando a movimentação do jogador contribui para a realização de ações ofensivas da equipe atrás da linha da bola.

d- Quando a movimentação do jogador auxilia no avanço da equipe para o meio campo ofensivo.

Mal sucedida (-)

a-Quando a movimentação do jogador não permite que outros companheiros participem das ações da equipe ou se aproximem do centro de jogo.

b-Quando a movimentação do jogador não the faculta a possibilidade participar de uma ação ofensiva/defensiva subsequente.

c- Quando a movimentação do jogador não contribui para a realização de ações ofensivas da equipe atrás da linha da bola.

d- Quando a movimentação do jogador não auxilia no avanço da equipe para o meio campo ofensivo.

\section{Contenção}

\section{Indicadores de Desempenho}

Bem sucedida (+)

a-Impedir o remate / b-Impedir progressão / c-Retardar ação oponente / d-Direcionar o portador da bola p/ zonas menor risco.

Mal sucedida (-)

a-Não impedir o remate / b-Não impedir progressão / c-Não retarda a ação oponente / d-Não direcionar o portador da bola p/zonas menor risco.

\section{Descrição dos Indicadores}

Bem sucedida $(+)$

a-Quando a movimentação/oposição do jogador impede que o portador da bola remate à baliza.

b-Quando a movimentação do jogador impede que o portador da bola progrida em direção à baliza.

c-Quando a movimentação do jogador retarda a ação ofensiva adversária, permitindo que a sua equipe se organize defensivamente.

d-Quando a movimentação do jogador direciona o portador da bola para zonas de menor risco.

Mal sucedida (-)

a-Quando a movimentação/oposição do jogador não permite impedir o remate do portador da bola à baliza.

b- Quando a movimentação/oposição do jogador não permite conter a progressão do portador da bola em direção à baliza.

c- Quando a movimentação do jogador não permite retardar a ação ofensiva adversária, não permitindo que a sua equipe se organize defensivamente.

d- Quando a movimentação do jogador não permite direcionar o portador da bola para zonas de menor risco.

\section{Cobertura Defensiva}

\section{Indicadores de Desempenho}

Bem sucedida $(+)$

a-Posicionar entre o jogador de contenção e a baliza / b-Possibilitar $2^{\mathrm{a}}$ contenção / c-Obstruir linhas de passe.

Mal sucedida (-)

a-Não posicionar entre o jogador de contenção e a baliza / b-Não possibilitar $2^{\text {a }}$ contenção / c-Não obstruir linhas de passe.

Descrição dos Indicadores

Bem sucedida $(+)$

a- Quando a movimentação do jogador permite um posicionamento entre o jogador que realiza a contenção e a baliza, na metade mais ofensiva do centro de jogo.

b- Quando a movimentação do jogador permite que ele constitua um novo obstáculo ao portador da bola, caso o jogador que realiza a contenção seja driblado.

c- Quando a movimentação do jogador permite obstruir ou interceptar linhas de passe do portador da bola a outro adversário.

Mal sucedida (-)

a- Quando a movimentação do jogador não permite um posicionamento entre o jogador que realiza a contenção e a baliza, na metade mais ofensiva do centro de jogo.

b- Quando a movimentação do jogador não permite que ele constitua um novo obstáculo ao portador da bola, caso o jogador que realiza a contenção seja driblado.

c- Quando a movimentação do jogador não permite obstruir ou interceptar linhas de passe do portador da bola a outro adversário.

\section{Equilíbrio}

\section{Indicadores de Desempenho}

Bem sucedida (+)

a-Estabilizar zonas laterais CJ / b-Obstruir linhas de passe / c-Estabilizar M-OCJ / d-Interferir no portador M-OCJ / e-Obstruir linhas de passe.

Mal sucedida (-)

a-Não estabilizar zonas laterais CJ / b-Não obstruir linhas de passe / c-Não estabilizar M-OCJ / d-Não interferir portador M-OCJ / e-Não obstruir linhas de passe. 
Anexo 1: continuação

Equilíbrio (cont.)

\section{Descrição dos Indicadores}

Bem sucedida $(+)$

a-Quando a movimentação do jogador permite criar estabilidade defensiva nas relações de oposição nas zonas laterais em relação ao centro de jogo(através da marcação de adversários que podem receber a bola ou da obstrução de linhas de passe), impedindo a progressão ofensiva adversária.

b-Quando a movimentação do jogador permite obstruir ou interceptar linhas de passe do portador da bola a outro adversário localizado nas zonas laterais ao centro de jogo.

C-Quando a movimentação do jogador permite criar estabilidade defensiva nas relações de oposição na metade menos ofensiva do centro de jogo, através da marcação de adversários que podem receber a bola ou da obstrução de linhas de passe.

d-Quando a movimentação de recuperação defensiva do jogador (metade menos ofensiva do centro de jogo) interfere na ação do portador da bola criando dificuldades para a sequência ofensiva adversária ou facilitando a recuperação da bola por parte da sua equipe.

e-Quando a movimentação do jogador permite obstruir ou interceptar linhas de passe do portador da bola a outro adversário dentro da metade menos ofensiva do centro de jogo.

Mal sucedida (-)

a-Quando a movimentação do jogador não permite criar estabilidade defensiva nas relações de oposição nas zonas laterais em relação ao centro de jogo (através da marcação de adversários que podem receber a bola ou da obstrução de linhas de passe), impedindo a progressão ofensiva adversária.

b- Quando a movimentação do jogador não permite obstruir ou interceptar linhas de passe do portador da bola a outro adversário localizado nas zonas laterais ao centro de jogo.

c-Quando a movimentação do jogador não permite criar estabilidade defensiva nas relações de oposição na metade menos ofensiva do centro de jogo, através da marcação de adversários que podem receber a bola ou da obstrução de linhas de passe.

d- Quando a movimentação de recuperação defensiva do jogador na metade menos ofensiva do centro de jogo não interfere na ação do portador da bola, dificultando a recuperação da bola por parte da sua equipe.

e- Quando a movimentação do jogador não permite obstruir ou interceptar linhas de passe do portador da bola a outro adversário dentro da metade menos ofensiva do centro de jogo.

\section{Concentração}

\section{Indicadores de Desempenho}

Bem sucedida (+)

a-Diminuir profundidade adversária / $b$-Direcionar o jogo adversário $\mathrm{p}$ / zonas de menor risco.

Mal sucedida (-)

a-Não diminuir profundidade adversária / b-Não direcionar o jogo adversário p/ zonas de menor risco.

Descrição dos Indicadores

Bem sucedida (+)

a- Quando a movimentação do jogador auxilia a equipe a diminuir a amplitude ofensiva adversária (ou espaço de jogo efetivo adversário) na sua profundidade.

b- Quando a movimentação do jogador auxilia a equipe a direcionar o jogo adversário para zonas do campo de jogo que representam menor perigo à baliza.

Mal sucedida (-)

a- Quando a movimentação do jogador não auxilia a equipe a diminuir a amplitude ofensiva adversária (ou espaço de jogo efetivo adversário) na sua profundidade.

b- Quando a movimentação do jogador não auxilia a equipe a direcionar o jogo adversário para zonas do campo de jogo que

\section{representam menor perigo à baliza.}

\section{Unidade Defensiva}

\section{Indicadores de Desempenho}

Bem sucedida $(+)$

a-Diminuir amplitude adversária / b-(Re)equilibrar a organização defensiva / c-Contribuir p/ações defensivas atrás da linha da bola / d-

Aproximar a equipe ao CJ / e-Participar ação subsequente.

Mal sucedida (-)

a-Não diminuir amplitude adversária / b-Não (re)equilibrar a organização defensiva / c-Não contribuir p/ações defensivas atrás da linha

da bola / d-Não aproximar a equipe ao CJ e-Não participar ação subsequente.

Descrição dos Indicadores

Bem sucedida (+)

a- Quando a movimentação do jogador promove a diminuição da amplitude ofensiva adversária na sua largura e/ou profundidade.

b- Quando a movimentação do jogador permite equilibrar ou reequilibrar constantemente a repartição de forças da organização

defensiva consoante às situações momentâneas de jogo (setor subsequente à metade mais ofensiva do centro de jogo).

c- Quando a movimentação do jogador contribui para a realização de ações defensivas da equipe atrás da linha da bola (através da marcação de adversários que podem receber a bola ou da obstrução de linhas de passe).

d- Quando a movimentação do jogador propicia que outro jogador de defesa participe das ações no centro de jogo.

e- Quando a movimentação do jogador lhe faculta a possibilidade de participar de uma ação defensiva/ofensiva subsequente.

Mal sucedida (-)

a- Quando a movimentação do jogador não promove a diminuição da amplitude ofensiva adversária na sua largura e/ou profundidade.

b- Quando a movimentação do jogador não permite equilibrar ou reequilibrar constantemente a repartição de forças da organização

defensiva consoante às situações momentâneas de jogo (setor subsequente à metade mais ofensiva do centro de jogo).

c- Quando a movimentação do jogador não contribui para a realização de ações defensivas da equipe atrás da linha da bola (através da marcação de adversários que podem receber a bola ou da obstrução de linhas de passe).

d- Quando a movimentação do jogador não propicia que outro jogador de defesa participe nas ações que ocorrem no centro de jogo.

e- Quando a movimentação do jogador não lhe faculta a possibilidade participar de uma ação defensiva/ofensiva subsequente. 